\title{
CORRELATION OF SHYNESS WITH SCHOOLING, RESIDENTIAL LOCALITY AND SOCIO- ECONOMIC STATUS AT GRADUATION LEVEL IN PAKISTAN
}

\author{
Saeed Anwar \\ Mumtaz Ali ${ }^{* *}$ \\ Azadi Fateh Muhammad ${ }^{* * *}$
}

\begin{abstract}
Shyness affects and influences the performance of the learners at school and college level. There are different correlates and reasons of shyness. Zimbardo states that Shyness is a vague concept which has many interpretations and definitions. One definition which is very renowned is that "The person, male or female, who is nervous, worried, and uncomfortable in the gathering or presence of others, is called shy". The objectives of this research study were as: (1) to investigate the relationship of schooling system with shyness (2) to investigate the relationship of residential locality with shyness (3) to check relationship of Socio- Economic status with shyness (4) To rank the correlates of shyness. Overall 252 students from graduation of Indus group of Colleges from Rawalpindi and Islamabad were the population of the study and 42 students were selected through simple random sampling technique as a sample for the study. The researcher got the data with the help of personal visits to the colleges. Questionnaire for measuring shyness was used by the researcher for this research study. Another self developed questionnaire or instrument was used to know the correlates of shyness. Chisquare test of independence was used for data analysis. The results of the study showed that shyness depended upon these correlates of shyness as (1) residential locality (2) Schooling system (3) socio-economic status of the learners. Shyness depends upon above mentioned correlates. In order to remove this problem of shyness, some steps should be taken as learners or students may not be blamed or punished without any reason. Learners should be encouraged and motivated.
\end{abstract}

Keywords: Shyness, socio-economic status, schooling, residential locality, classroom performance

\section{Introduction}

There are numerous styles of learning and methods of teaching. Every learner has his own style of learning as different styles of learning exist as: visual; auditory; and kinaesthetic styles of learning. Some students are more visual leaner then auditory and

\footnotetext{
* Saeed Anwar, Ph.D., Assistant Professor, COMSATS Institute of Information Technology, Islamabad

** Mumtaz Ali, Ph.D., Assistant Professor, COMSATS Institute of Information Technology, Islamabad

**** Aazadi Fateh Muhammad, Ph.D., Assistant Professor, Department Mass Communication, Faculty of Social Sciences, Federal Urdu University of Arts, Science and Technology, Karachi

${ }^{1}$ Crozier, W.R.. "Shyness and Self esteem in middle childhood", British Journal of educational Psychology, 21,118-121 (1995)
} 
some are kinaesthetic learner then visual leaner. There are mixed ability learners as outstanding, brilliant low tech students, high tech students, and average students, competent, teasing, diffident, shy and confident students. Those students, who are confident, may ask certain questions in order to remove their confusion and misunderstanding. Confidence is considered very important for success in all fields of life. Shyness is conjectured great hurdle in learning and success ${ }^{2,3}$.

Socialization is considered as an indication and integral characteristic of confident person or learner. On the other hand, Shy person avoids socialization and does not participate in social gathering or academic activity of learning. There are many people, who are suffering from severe problem of Social anxiety. They feel great problem and stress in social interaction due to Social anxiety. Social anxiety has different types as: audience anxiety; discomfiture; nervousness; shame; and shyness ${ }^{4}$. Shyness is considered as uneasiness and reticence in the attendance of others as seniors or authoritative figures ${ }^{5}$.

Shyness in a classroom is noticed as by sitting far from the teacher or professor. More over such students don't participate in any discussion in the classroom. Such students prefer to listening rather than talking about topic or participating in group discussion ${ }^{6}$. There are some shy people who are quite difficult to identify or point out. Such people avoid proper eye contact. Their body language, behaviour, and expression change after talking to anybody. Such people may appear to others that they are social, confident and extroverted but actually they are "not really social or confident". There is a physiological measure in assessing social phobia of any person as Heart beat or Heart rate during social interaction or conversation ${ }^{7}$.

Every individual is having different individual traits and characteristics which make him different and unique among all human beings. It is a fact that all human beings are different from each other even a lot of differences are observed among real brothers and sisters. Consequently all human beings have different shades of personality. Some of them are very social and some of them are antisocial. Some people are helpless in being social and some are sick of loneliness and privacy. Many prefer to be in contact with others and many show reserve attitude ${ }^{8}$.

In different schools, colleges, universities and learning institutions, it is noticed that there are diverse types of learners and students. The students perform, work and react in

\footnotetext{
${ }^{2}$ Carducci, B. J., "The shyness workbook: 30 days to dealing effectively with shyness", Champaign, IL: Research Press (2005:194).

${ }^{3}$ Carducci, B.J., and Zimbardo, P.G.”Are you shy?" Psychology today, (December 1995: 34, 41, 64,66,68,78, 82)

${ }^{4}$ Buss, A.H. "A theory of shyness', in W.H. Jones, J.M. Cheek, and S.R. Briggs (eds) Shyness: Perspective on Research and Treatment", New York: Plenum (1986: 23-46)

${ }^{5}$ Ibid

${ }^{6} \mathrm{Ibid}$

${ }^{7}$ Scott, R., "Shyness, Social acceptance \& self-esteem in early adolescence: Interrelationships \& the role of parents", Dissertation doctor of philosophy Athens, Georgia (2003:159)

${ }^{8}$ Ibid
} 
dissimilar ways, during classes and learning process. The teacher, lecturer and professor observe and notice the difference of learning style of every individual and learner. This variation and difference is the ultimate result of various factors, correlates and reasons. The researcher decided to explore and investigate this interesting topic, keeping in view the worth and importance of the crucial topic.

\section{Objectives of the study}

The objectives of the research study were:

1. To investigate the relationship of schooling system with shyness.

2. To investigate the relationship of residential locality with shyness.

3. To check relationship of Socio- Economic status with shyness.

4. To rank the correlates of shyness.

\section{Significance of the study}

This research study is very worthy and important because it could help a lot of students, education planners, professors, lecturers and school teachers. This research study might improve teaching-learning process and teaching-learning environment. School, college, and university learning environment might be enhanced by using the results of the research study that shyness was a barrier in success which could be removed by visionary leadership and psychotherapy. This research study could be very productive and advantageous for all relevant educationists. Learners undergo from various educational issues, peer pressure, stress and ethical problems consequently it is professional duty of a teacher, instructor, lecturer, facilitator or professor to cure it or remove those chronic problems of the learners. Students may take assistance from this study. According to many Western writers, shyness was a hindrance in the way of success in education. After removing this problem, student can attain their educational objectives and make their educational and professional careers bright. It may also lead to further research in this area.

\section{Review of Relevant Literature}

There is enormous variety of student's as brilliant students, intellectual, courageous, industrious, judicious, submissive, assiduous, hesitant, nervous, coward, terrified, but some of the students are very positive and some students are very bashful and shy. The performance of students is affected by confidence and shyness. There are different correlates and reasons of shyness.

Participation in social gatherings and educational groups is considered very important for active learning. It was observed that due to nervousness and shyness, the person would not involve himself in any community activity, learning activity or social gathering. Social anxiety has four types as: audience anxiety; discomfiture; nervousness; shame; and shyness. Audience anxiety is, when the speaker sees small number of 
audience or big number of audience, and then he feels fear is called audience anxiety ${ }^{9}$. Discomfiture is also such type of social anxiety, when someone feels awkward or uncomfortable in the presence of others. Nervousness is another type of social anxiety, in which a person feels nervous due to social gathering. Shyness is considered as being uncomfortable and uneasy in the attendance of others. Shyness is psychological problem which may be treated in better way to avoid it ${ }^{10}$.

Introvert, timid and shy people wish to select such type of careers, where there is minimum chance of social interaction ${ }^{11}$. Social interaction for shy people is so difficult that, it produces social anxiety ${ }^{12}$. According to a researcher, shy students have passive approach to their professional and educational improvement and abortive to exercise accessible resources such as advisors, coaches, mentors or counsellors for the reason that of their apprehension and horror of higher authorities. The tendency and approach to avoid interaction led them to deterrent and discouragement. For instance, if they managed to cross the threshold of higher education, then they try to select a career with slightest community interaction. They wish to seek jobs as computer-related work, accounting and an assortment of types of research etc. it is observed that many people with such social anxiety and social pressure dropped out of school early and some shy people get their graduate equivalency degree. All shy students and learners can be taught about social skills and shy people should be taught about handling new and unpredictable situations ${ }^{13}$. All those students, who are quite skilful in dealing all type of enigmatic situations, are very successful in all maters and all walks of life. In modern age, good communication skill is considered inevitable and unavoidable for success in all fields of life ${ }^{14}$.

Shyness is a concept which has various shades due to its abstractness and obscurity. There are so many authors and writers who have interpreted the concept of shyness in different ways which gives the impression of fuzziness. Commonly interpolation, socioeconomic status influences the mind, approach and performance of the individual. According to many authors, social status, socio-economic status, education of parents, residential locality of the people, the schooling of the learner, the family size and structure of that family, traditions, customs and trends are considerable factors for shyness. Shyness is the state of mind when someone is uneasy to communicate or interact with others. If he/she tries to communicate then communication is ineffective communication which caused miscommunication. Such people want to remain reserve due to social anxiety and social pressure ${ }^{15}$.

\footnotetext{
${ }^{9}$ Zimbardo, P.G. "The Stanford Shyness Project", in W.H. Jones, J.M. Cheek and S.R. Briggs (eds) Shyness: Perspectives on Research and Treatment, New York: Plenum Press (1986: 17 - 25)

${ }^{10}$ Ibid.

${ }^{11}$ Marshall, J. R.. Social Phobia: "From Shyness to Stage Fright”. New York: Basic Books (1994:76)

${ }^{12}$ Ibid.

${ }^{13}$ Bruch M.A. Gorsky. J.M. Collins, T.M. and Berger, P.A., "shyness and sociability Re-examined a multi-component analysis", journal of personality and psychology 57:904-15 (1989)

${ }^{14}$ Bruch, M.A., "Familial and development antecedents of social phobia: issues and findings," Clinical Psychology Review, 9:37-47 (1989)

${ }^{15}$ Volbrecht, M. M., \& Goldsmith, H., "Early temperamental and family predictors of shyness and
} 
There are various definitions of shyness, which are stated here. According to a renowned writer" ${ }^{16}$ shyness is "The propensity to keep away from contact or acquaintance with other people is nervousness or bashfulness." Shyness is an indistinguishable concept which has many interpretations and definitions ${ }^{17,18}$. He further states that "The person, male or female, who is nervous, worried, and uncomfortable in the gathering or presence of others, is called shy". According to ${ }^{19}$, in his dictionary Academic Dictionary of Psychology "shyness is an individual's discomposure and selfconsciousness in interpersonal relations that interferes with pursuing interpersonal or professional goals $\left(5^{\text {th }}\right.$ edition). Oxford Advance Learners dictionary ${ }^{20}$ states, that shy person is worried or uncomfortable about gathering and interpolation to other human beings. Another interpretation is that when any person, who is effortlessly terrified and not prepared to come close to people for interaction, is considered shy. The Oxford English dictionary mentions that the most primitive recorded words used in an Anglo Saxon poem in black and white around 1000 A.D, in which shyness meant "without difficulty frightened" so the person, who is easily frightened by social interaction ${ }^{21}$.

It is a natural phenomenon that all human beings are different from each other in various aspects. All individuals have particular features, intrinsic worth and individuality persona. Some of them are very communal, gregarious persons; humanitarian, philanthropic, altruistic and some of them are very recluse, unsociable, detractor and such people like lonesomeness and privacy. There are different styles of learning in recent age. In modern era, traditional methods of learning are obsolete. These days such methods of learning are very famous as activity base learning, group activity, peer work, team work and class room work etc. It is observed that there are different types of students who prefer different styles of learning as visual, auditory and kinaesthetic. Students perform and respond in dissimilar ways, according to their competency, calibre and mentality during learning process. This dissimilarity and divergence in personality, temperament, outlook and manner is noticeable for school teachers, lecturer, professor and educational manager or administrator ${ }^{22}$.

According to the opinions of class instructor, class room facilitator or teachers that some learners are self-assured, audacious, and frank and such learner are extremely at ease in a classroom during teaching-learning process. Such students frequently ask certain questions in order to clarify their concepts and these confident learners contribute in all activities of the classroom. Some of the learners stay behind and they are passive or in

anxiety" Developmental Psychology, 46(5), 1192-1205 (2010)

16 Wood, J., "Effect of anxiety reduction on children's school performance and social

adjustment", Journal Developmental psychology, 42(2), 345-349 (2006)

${ }^{17}$ Zimbardo, P.G. "Shyness: What it is, what to do about it, Reading", MA: Addison-Wesley (1977:71)

${ }^{18}$ Bruch, M.A., Giordano, S. and Pearl, L., "Difference between fearful and self-conscious shy subtypes in background and current adjustment", Journal of Research in Personality, 20:172-86, (1986)

${ }^{19}$ Zimbardo, P.G., Pilkonis, P.A. and Norwood, R.M. "The social disease called Shyness", Psychology Today, 8:68-72 (1975)

20 “Oxford Advanced Learner's Dictionary" (6 ${ }^{\text {th }}$ ed.). New York, Oxford University Press (2000:83)

${ }^{21} \mathrm{Ibid}$

${ }^{22}$ Rubin, K. H., \& Coplan, R. J.. "The development of shyness and social withdrawal” New York: The Guilford Press (2010:324). 
active in the class and they are not energetically or vigorously participating in class room activities during activity base learning. Such types of learners or students are conjectured reserved, introvert and scared, who are disinclined to ask any questions for increasing their information. Such pupils undergo uncomfortable at the time of involvement or contribution in the activity of class. Shy or unsocial students consider that silence is best tool to keep away from humiliation or mortification. When class room instructor or facilitator provides opportunity to such shy students to articulate or communicate their views, then the shy students demonstrate eccentric expressions as they become speechless, astonish, nervous, breathless, trembling, full of perspiration, self-conscious, unsteady and protracted. These learners experience fretfulness and it is incredibly complicated for them to articulate their real thoughts and pent up emotions $^{23,24}$.

Shyness is very painful and torturing experience because many observers and viewers describe the situation in a ridiculous and derogatory way. Many people guess that these shy people are less talented and less motivated and less skilful, which is quite discouraging thing for shy people. It is a fact that shy people avoid frequently many educational situations but it does not mean that they are less intelligent or less capable. Moreover, shy learners cannot utilize their innate qualities and characteristics to full extend consequently such people remain far behind in their professional and academic careers. Shy students cannot demonstrate their knowledge in proper way in class as a result some teachers develop an opinion that these students are dull and careless in their studies. Shy students face many invisible problems as psychological, emotional, intellectual, socials and educational. Shy students face great difficulty in class participation, asking questions from teachers, collaboration with peers or class fellows. Shy students generally develop very weak relationship with peers, seniors and junior fellows. Shy students need great help from staff, teachers, peers and parents. Moreover Cognitive-behavioral therapy and medications can also be used as a treatment of the shy students but it can be used outside the institution or school or college ${ }^{25}$.

According to $^{26}$, shy Children usually feel they are being evaluated by visitors or observers and they have reservations of being disapprovingly or negatively reviewed and discarded by them, which actually lead to the withdrawal and avoiding social interaction to the situation. Such children prefer solitude and isolation due to complex as inferiority complex so shy children restrict themselves to their room and avoid social interaction in any form even they avoid parties with their relatives ${ }^{27,28}$.

\footnotetext{
${ }^{23}$ Ibid

${ }^{24}$ Zimbardo, P.G., Pilkonis, P.A. and Norwood, R.M., "Shackles of Shynes", Psychology Today, UK edition, 1 (6): 24-7 (1975)

${ }^{25}$ Kimberley, Arbeau, Robert, Coplan, "Shyness in adolescents" Ottawa; Carleton University, (2005:39)

${ }^{26}$ Crozier, W. R., \& Alden, L. E., "The essential handbook of social anxiety for clinicians". West Sussex, England: John Wiley \& Sons LTD (2005:217)

${ }^{27}$ Harris, P. R., "Shyness and psychological imperialism: On the dangers of ignoring the ordinary language roots of the terms we deal with", European Journal of Social Psychology, 14, 169-181 (1984)

${ }^{28}$ Zimbardo, P.G., Pilkonis, P.A. and Norwood, R.M., "The Silent Prison of Shyness", Office of Naval Research Technical Report Z-17, Stanford University (1974:83)
} 
Shyness occurs at diverse levels and appears dissimilar between people. There are numerous categories connected with shyness: First category is low approach; Conflicted shyness is category no second; the third category is Fearful shyness; the final category is Slow to warm up, in which feelings of shy person will fall down after being engrossed in the social interaction with people. According to a writer, who had written much regarding shyness ${ }^{29}$, states that shyness in children is very much normal thing from five months to onward till two years. According to him, it is a part of development regarding personality and socialization. Shyness is serious problem after two years lives, when children are suppose to be social. It is observed that the life of shy children is affected as school life, social life, personal life and domestic life. A shy learner is very disturb and uncomfortable in the presence of others and particularly, when he is suppose to perform or present anything. Such an individual shy person cannot handle any form of castigation in a reasonable way and he does hardly anything to defend himself $f^{30,31}$.

There are different reasons and causes of shyness among adults and children. These causes may be as: biological, environmental, overall critical nature of parents, teachers, professors, class fellows, juniors, seniors, peers or relatives etc. More over overall low confidence in nature of an individual could be the cause of shyness. Many critics and authors stress on effective communication skills of an individual. Whenever any individual is not good at interpersonal skills and effective communication, then he/she will suffer a lot because miscommunication may cause great damage to personality, self respect, self esteem, dignity, reputation and impression of the person. Such learners feel gigantic difficulty in freely expressing themselves. During the process of learning, such students don't ask any question and they also don't give answers of the questions which they even know quite well. Even some of the learners have severe problem in writing skills as well. Some students cannot express themselves in good way due to any unknown fear and social anxiety so they remain aloof and in seclusion ${ }^{32}$.

The role of schooling system is also quite important in the development of personality and personal growth. Education is necessary for all and it is not only basic human right but also very crucial for personality growth. Any school, which is providing education, is actually an institution, where pupils are taught and trained under the kind supervision of trainer, teacher, advisor or mentor. Nevertheless, schooling system plays pivotal role in learning different things as socialization, personality development, confidence building, effective communication, good presentations skills, and skills of speech and all other important aspects of life ${ }^{33}$.

${ }^{29}$ Crozier, W. R., "Shyness and embarrassment: Perspectives from social Psychology", New York: Cambridge University Press (1990:212)

${ }^{30}$ Harris, P. R., "Shyness and psychological imperialism: On the dangers of ignoring the ordinary language roots of the terms we deal with", European Journal of Social Psychology, 14, 169-181 (1984)

${ }^{31}$ Crozier, W. R., \& Alden, L. E., "International handbook of social anxiety". West Sussex, England: John Wiley \& Sons LTD (2001:198)

${ }^{32}$ Carducci, B. J., "The shyness breakthrough: A no-stress plan to help your shy child warm up, open up, and join the fun", Emmaus, PA: Rodale (2003: 67)

${ }^{33}$ Scott, S., "The Medicalization of shyness: from social misfits to social fitness". Sociology of Health \& Illness, 28(2), 133-153 (2006) 
In Pakistan, two major languages are used as English or Urdu. These two languages are medium of instruction for learners. More over there are two types of schools, as Urdu medium schools which are providing education to the majority of the population. Another type of schooling is English medium schools, which provide education and schooling to particular class or section of society. The elite class in Pakistan prefers Beacon House School System, or City School System, Frobel's School System, Roots School System for their Children. The average or middle class send their children in Sadeeq Public schools, Asif Public schools or some low fee structured schools.

Shyness depends on socio-economic status of the individual. If the learner belongs to high socio-economic class then he or she will be confident, participative and proactive $^{34}$. On the other hand, if the learner belongs to low socio-economic class then he or she will be diffident, less participative and escapist. It is a reality the socio-economic status or class matters a lot in his personality formation and to be confident, bold or shy, diffident ${ }^{35}$.

Another correlate of shyness is living environment or residential locality. It is observed that surroundings, culture, residential locality put a great influence on personality of the learner. Those students, who belong to high socio-economic class and live in a posh area, were showing more confidence, will power and personal integrity. Such students were observed very successful in social interaction and social participation. Other learners, who belong to low socio-economic class or status, were not successful in social interactions and they were avoiding socialization and gathering ${ }^{36}$. Excessive parental evaluation is another cause of shyness. When parents are continuously evaluating the children, then the children become nervous, uncomfortable and shy ${ }^{37}$. In fact, children want support from their parents. Such students face great difficulty in interpersonal communication when parents behave very strictly. Parental education also matters a lot. If the parents are well educated as Masters or M.phil or Doctorate degree holders then they may guide their children in good way. But if the parents are not well educated or even illiterate then they may not be able to guide the children ${ }^{38}$.

\section{Methodology}

Research Design: This research is descriptive in nature. The data was collected by visiting the Indus group of colleges in Rawalpindi/Islamabad personally. It is a survey regarding Correlation of Shyness with schooling, residential locality and socioeconomic status at graduation level in Pakistan. The researcher forms the research hypothesis to test them for this research study.

\footnotetext{
${ }^{34}$ Arbeau, K. A., \& Coplan, R. J., "Shyness, teacher-child relationships, and socio-emotional adjustment in grade 1". International Journal of Behavioral Development, 34(3), 259-269. doi:EJ910777 (2010)

${ }^{35}$ Coplan, R. J., \& Arbeau, K. A.. "The stresses of a "brave new world": Shyness and school adjustment in kindergarten". Journal of Research in Childhood Education, 22(4), 377-390. doi:EJ805003 (2008)

${ }^{36}$ Buss, "The self across psychology: Self-recognition, self awareness, and the self-Concept", Annals of the New York Academy of Sciences, Vol. 818 (1993:62)

${ }^{37} \mathrm{Ibid}$

${ }^{38}$ Carducci, B. J., "What shy individuals do to cope with their shyness: A content analysis and evaluation of self-selected coping strategies", Israel Journal of Journal of Psychiatry and Related Sciences, 46,45-52 (2009)
} 
Participants: The participants of the study were 252 students from graduation of Indus group of Colleges from Rawalpindi and Islamabad were the population of this research study and 42 students were selected through simple random sampling technique as a sample for the study. The researcher got the data with the help of personal visits to the selected colleges. Before collecting the data, the consent was taken in written form, from all the respondents. All the respondents were briefed about the importance of this study.

Instruments: Two questionnaires were used as an instrument for data collection. One questionnaire of twenty eight items which was developed by ${ }^{39}$ and another questionnaire had five items, was self developed questionnaire which was about correlates of shyness. A 28 items questionnaire which was developed by ${ }^{40}$ was used to measure shyness and to know about social interaction, psychological condition, emotional condition, self esteem and self-consciousness of students. Moreover self developed questionnaire was given to the students to know about their residential locality, schooling, parental education, family structure and socio-economic status of respondents.

Reliability and Validity: The questionnaires were got validated from 25 faculty members and the questionnaires were revised accordingly. After correction, the questionnaires were finalized. The researcher held a pilot testing to find out the reliability of the instruments. 15 teachers and 20 students were selected for pilot testing. The both instruments were found reliable.

\section{Data Collection and Data Analysis}

\section{Data Collection}

The data were collected through personal visits to the selected Colleges. The students were contacted in Indus group of Colleges from Rawalpindi and Islamabad. Confidentiality was ensured to the students and the outcomes of the study were explained to them. Subjects were individually briefed and tested at relatively free place in the colleges.

\section{Data Analysis}

After getting required data from respondents, the data was analysed by using appropriate statistical tools. First of all 28 items questionnaire was used for measuring shyness which was developed by Crozier in 1995 . For each yes response 10 marks were given and zero mark was given for no response. Moreover second instrument was a self developed questionnaire which was used to find out the correlates of shyness as socioeconomic status, schooling system, and residential locality. Chi-square test of independence was used to analyse the data. The correlates of shyness were ranked according to the analysis of the data.

\footnotetext{
${ }^{39}$ Crozier, W.R.. "Shyness and Self esteem in middle childhood", British Journal of educational Psychology, 21,118-121 (1995).

${ }^{40}$ Crozier, W.R., "Shyness and self-esteem”, British Journal of Social Psychology, 20:220-2 (1981)
} 


\section{Measuring Shyness and Analysis of Correlates of Shyness}

The researcher has used two instruments for measuring shyness and to know about correlates of shyness. Shyness was measured by using a questionnaire of Crozier and a self developed questionnaire was given to the students to know about correlates of shyness as their residential locality, schooling, and socio-economic status. After measuring shyness, the correlates of shyness were checked and their association was checked with shyness by using chi-square test of independence.

\section{Hypothesis-1:}

$H_{0}$ : There is no significant relationship between shyness and socio-economic status.

$H_{1}$ : There is significant relationship between shyness and socio-economic status.

The contingency table is given to show comparison of Shyness status and Socioeconomic Status of the students.

Contingency table 1: Comparison of Shyness status and Socio-economic Status

\begin{tabular}{|l|l|l|l|l|}
\hline Shyness & Upper Class & Middle Class & Lower Class & Total \\
\hline High shyness & 2 & 3 & 9 & 14 \\
\hline Low shyness & 17 & 3 & 8 & 28 \\
\hline Total & 19 & 6 & 17 & 42 \\
\hline \multicolumn{2}{|l|}{$\chi^{2}$ at $0.05=$} \\
\hline
\end{tabular}

$\chi^{2}(r-1)(c-1) \alpha=\chi^{2}(2-1)(3-1) 0.05=\chi^{2} 2(0.05)=5.99$

$\chi^{2}=\sum \frac{\left(f_{0}-f_{e}\right)^{2}}{f_{e}}$ 


$$
=8.01
$$

Socio-economic status depends on income and amenities of life; it contributes in attitude of shyness. The table shows the respondents belonging to upper class had less symptoms of shyness and those who belonging to lower class had higher score of shyness. It shows that shyness depends on socio-economic status and there is association between shyness and socio-economic status. Since $\chi_{\text {Cal }}^{2}$ is greater 8.01 than $\chi_{t a b}^{2}$ so the null hypothesis is rejected and concluded that there is an association between shyness and socio economic status. The socio-economic status influence the personality of students and it has impact on shyness.

\section{.Hypothesis-2:}

$H_{0} \quad$ There is no significant relationship between shyness and residential locality.

\section{$H_{1} \quad$ There is significant relationship between shyness and residential locality.}

The contingency table is given to show comparison of Shyness status and residential locality of the students.

\section{Contingency Table 2: Comparison of Shyness and Residential Locality}

\begin{tabular}{|l|l|l|l|l|}
\hline Shyness & Developed & $\begin{array}{l}\text { Average } \\
\text { Developed }\end{array}$ & $\begin{array}{l}\text { Under } \\
\text { Developed }\end{array}$ & Total \\
\hline High shyness & 1 & 1 & 12 & 14 \\
\hline Low shyness & 24 & 3 & 1 & 28 \\
\hline Total & 25 & 4 & 13 & 42 \\
\hline \multicolumn{1}{|c|}{ df $=2$} & \multicolumn{3}{c|}{$\chi^{2}$ at $0.05=$} \\
\hline
\end{tabular}

$$
\begin{aligned}
& \chi^{2}(r-1)(c-1) \alpha=\chi^{2}(2-1)(3-1) 0.05=\chi^{2} 2(0.05)=5.99 \\
& \chi_{C a l}^{2}=\sum\left[\frac{f_{0}^{2}}{f e}\right]-N
\end{aligned}
$$




$$
=30.315
$$

The table No 2 shows that the respondents belonging to average developed or under developed residential areas were shyer as compared to those residing in developed or posh locality. If students belong to upper class, living in good locality and enjoying all privileges and facilities of life then they would be confident but those who are deprived from basic requirements and needs, they would be diffident and shy. It shows that shyness depends on residential locality and there is an association between shyness and parental education. Since $\chi_{\text {Cal }}^{2}$ is greater 30.315 than $\chi_{\text {tab }}^{2}$ so the null hypothesis is rejected and concluded that there is an association between shyness and residential locality of the learners or students.

\section{Hypothesis-3:}

$H_{0} \quad$ There is no significant relationship between shyness and Schooling system.

\section{$H_{1} \quad$ There is significant relationship between shyness and Schooling system.}

The contingency table is given to show comparison of Shyness status and schooling of the students or learners.

\section{Contingency table 3: Comparison of Shyness and schooling}

\begin{tabular}{|l|l|l|l|}
\hline Shyness & Govt Schooling & Private Schooling & Total \\
\hline High shyness & 10 & 4 & 14 \\
\hline Low shyness & 6 & 22 & 28 \\
\hline Total & 16 & 26 & 42 \\
\hline
\end{tabular}

$\mathrm{df}=1 \quad \chi^{2}$ at $0.05=$

3.84

$\chi^{2}(r-1)(c-1) \alpha=\chi^{2}(2-1)(2-1) 0.05=\chi^{2} 1(0.05)=3.84$

$\chi_{\text {Cal }}^{2}=\sum\left[\frac{f_{0}^{2}}{f e}\right]-N$

$=10.7$ 
The schooling plays an important role in the formation of personality of children. The above mentioned table shows that the respondents having schooling from government schools were shyer as compared to respondents graduating from private schools. In private school, students get more attention, reverence and affection as compared to government school. In government schools, students get less attention due to large classes and over enrolment. It shows that shyness depends on schooling system and there is an association between shyness and schooling system.

Since $\chi_{\text {Cal }}^{2}$ is greater 10.7 than $\chi_{\text {tab }}^{2}$ so the null hypothesis is rejected and concluded that there is an association between shyness and schooling system. After using chisquare test of independence, the researcher came to know about the ranking of correlates of shyness. Keeping in view the results of chi-square test of independence, it was the order of ranking of correlates of shyness as residential locality, schooling, and socioeconomic status. The values of chi-square test of independence were given as residential locality was 30.315 , schooling is 10.7 , and socio-economic status was 8.01 . Consequently it was observed that residential locality ranked as first and schooling came at second number and socio-economic status stood at number three.

\section{Findings}

After analyzing the data, the important findings of the study are as: when shyness of learner increases, the performance of the learner or students decreases; and as shyness of students decreases, the class room performance of students increases. Moreover, an association was found between shyness and socio-economic status of students. Shyness depends upon socio-economic status. Socio-economic status depends on income and amenities of life; it contributes in attitude of shyness. The findings show the respondents belonging to upper class had less symptoms of shyness and those who belonging to lower class had higher score of shyness. Another finding of this research is that there is association between shyness and schooling system. Shyness depends upon schooling system as well. The schooling system plays an important role in child's formation. It was found that the respondents having schooling system from government schools were shyer as compared to respondents graduating from private schools system. In private school, students get more attention, reverence and affection as compared to government school. There is association between shyness and residential locality. Shyness depends upon residential locality. It was found that the respondents belonging to average developed or under developed residential areas were shyer as compared to those residing in developed locality. If students belong to upper class, living in good locality and enjoying all perk, privileges and facilities of life then they would be confident but those who are deprived from basic requirements and needs, they would be diffident and shy. The findings of the research show this ranking order of the correlates of shyness as (1) residential locality (2) schooling system (3) socio-economic status.

\section{Summary}

The analysis demonstrates that academic performance and class room performance is affected by level of shyness. The objectives of the research were as: 1) to investigate the relationship of schooling with shyness; 2) to investigate the relationship of 
residential locality with shyness; 3 ) to check relationship of socio- economic status with shyness; 4) To rank the correlates of shyness. Overall 252 students of Indus Colleges from Graduation were the population of this research study and 42 students were selected through simple random sampling technique as a sample for the study. The data were gathered through visiting personally to the selected colleges and institutions. The researcher used shyness questionnaire of Crozier for measuring shyness for this study. Moreover a self developed questionnaire was used to know the correlates of shyness. Chi-square test of independence was used for data analysis. All the achieved results after analysis obviously demonstrate and supported the hypotheses that shyness has sufficient effect on performance in classroom and performance in academic area. The term exams and monthly test scores show that less shy students perform better as compared to more shy students. The results of this research study show that those students or learners, who are diffident, hesitant or shy have the negatively influence on their educational and performance of classroom, because such type of attitude as shyness is a gigantic obstruction and hurdle in attaining well or excellent grades in educational career. Such type of students, who are reluctant to ask questions or hesitant to remove their confusion; remain far behind from confident students in competition. Such types of students hesitate to participate or involve themselves in class room activities or discussion and in class room they remain aloof and stranger. It is ultimate truth that lack of information and knowledge is another cause of shyness and to be less confident.

\section{Conclusions}

In this research study forty-two students were selected as respondents for this study from Indus group of Colleges of Rawalpindi and Islamabad Campuses. The data of forty-two students were analyzed. The subjects filled out 28 items questionnaire which was developed by ${ }^{41}$ and five items self-developed questionnaire which was about correlates of shyness. A 28 items questionnaire which was developed by him $^{42}$ was about to measure shyness and to know about social interaction, psychological condition, emotional condition and self-consciousness of students. Moreover self-developed questionnaire was given to the students to know about their residential locality, schooling system, and socio-economic status. These were conjectured correlates of shyness. All the null hypotheses were rejected pertaining to correlates of shyness. It was found that shyness depend upon residential locality, schooling system, and socioeconomic status. Chi-square test of independence was used to check the association between shyness and correlates of shyness and association was found. After using chisquare test of independence, the researcher came to know about the ranking of correlates of shyness. Keeping in view the results of chi-square test of independence, it was the order of ranking of correlates of shyness as residential locality, schooling system, and socio-economic status. The values of chi-square test of independence were given as residential locality was 30.315 , schooling system was 10.7 , and socio-economic status

\footnotetext{
${ }^{41}$ Coplan, R. J., Hughes, K., Bosacki, S., \& Rose-Krasnor, L., "Is silence golden? Elementary school teachers' strategies and beliefs regarding hypothetical shy/quiet and exuberant/talkative children". Journal of Educational Psychology, 103(4), 939-951. doi:EJ952354 (2011)

${ }^{42}$ Ibid
} 
was 8.01. Consequently, it was observed that residential locality as first and schooling system was second as correlate of shyness. More over socio-economic status came at number three in ranking of correlate of shyness. All these are the correlates of shyness and these correlates of shyness affect negatively the classroom performance of students. Shy students should be tackled tactfully.

The conclusions were drawn after analysing the data, that residential locality is important correlate of shyness. When students are living in good locality then they are more confident. Consequently there is strong association between shyness and residential locality. Shyness depends upon Socio-economic status and schooling system. There is association between shyness and Socio-economic status and schooling system of the respondents. When the students belong to good socio-economic status then they feel more confident and perform well. More over good schooling system plays important role in performance of students. Those students who study in private schools, they get more respect and attention consequently they become more confident and participative. Those students who study in government school, they get less attention due to overcrowded classes so they cannot ask questions in order to remove their confusion. Consequently they remain confused and shy.

\section{Recommendations}

The researcher has suggested some recommendations on the basis of already drawn findings and conclusions. The following recommendations are made for the administrators, parents, teachers, principals, lecturers, professors, and teachers as: the learners or students should not be punished or mentally tortured and criticized without any solid cause or logical reason. If the learner is wrong then he or she may be provided counselling in affectionate way. Administrators, managers' parents, teachers, principals, lecturers and professors should support, inspire and convince those children and students, who are introvert or shy, because they require ethical and moral support or assistance from their coach or mentors. Social interaction is very important for such shy children so such students should be provided chance or opportunity of social interaction. The importance of confidence may be highlighted because confidence is considered as the first step on the road of success if not then it will affect their educational career and professional career negatively. Another important suggestion is this that parents and community workers may be provided with coaching and mentoring so they improve their dealing with children and learners. Another practical recommendation is that shy students or less participative students may be provided a chance of power point presentation or oral presentation in front of class consequently such students will learn how to face class fellows, School, college, and university fellows in form of motivation and encouragement. It is professional and ethical responsibility and obligation of a teacher to assist and encourage such students, who are shy because it is a barrier in success. More over further research studies may be executed to know correlates of shyness in Pakistan because it requires more research in the particular area of shyness. Psychologists, scholars, paid organizations, Master or Doctoral researchers and educationists may explore on this crucial topic or problem and some practical solutions may be proposed for this severe problem. This chronic problem of shyness is very devastating and painful for learners and all shy learners want to get rid of this problem. 


\section{Bibliography}

Arbeau, K. A., \& Coplan, R. J., "Shyness, teacher-child relationships, and socioemotional adjustment in grade 1". International Journal of Behavioral Development, 34(3), 259-269. doi:EJ910777 (2010)

Bruch M.A. Gorsky. J.M. Collins, T.M. and Berger, P.A., "shyness and sociability Reexamined a multi-component analysis", journal of personality and psychology 57:90415 (1989)

Bruch, M.A., "Familial and development antecedents of social phobia: issues and findings," Clinical Psychology Review, 9:37-47 (1989)

Bruch, M.A., Giordano, S. and Pearl, L., "Difference between fearful and self-conscious shy subtypes in background and current adjustment", Journal of Research in Personality, 20:172-86, (1986)

Buss, "The self across psychology: Self-recognition, self awareness, and the selfConcept”, Annals of the New York Academy of Sciences, Vol. 818 (1993:62)

Buss, A.H. 'A theory of shyness', in W.H. Jones, J.M. Cheek, and S.R. Briggs (eds) Shyness: Perspective on Research and Treatment", New York: Plenum (1986: 23-46)

Carducci, B. J., "The shyness breakthrough: A no-stress plan to help your shy child warm up, open up, and join the fun", Emmaus, PA: Rodale (2003: 67)

Carducci, B. J., "What shy individuals do to cope with their shyness: A content analysis and evaluation of self-selected coping strategies", Israel Journal of Journal of Psychiatry and Related Sciences, 46,45-52 (2009)

Carducci, B. J., "The shyness workbook: 30 days to dealing effectively with shyness", Champaign, IL: Research Press (2005:194).

Carducci, B.J., and Zimbardo, P.G.”Are you shy?” Psychology today, (December 1995: $34,41,64,66,68,78,82)$

Coplan, R. J., \& Arbeau, K. A.. "The stresses of a "brave new world": Shyness and school adjustment in kindergarten". Journal of Research in Childhood Education, 22(4), 377-390. doi:EJ805003 (2008)

Coplan, R. J., Hughes, K., Bosacki, S., \& Rose-Krasnor, L., "Is silence golden? Elementary school teachers' strategies and beliefs regarding hypothetical shy/quiet and exuberant/talkative children". Journal of Educational Psychology, 103(4), 939-951. doi:EJ952354 (2011)

Crozier, W. R., "Shyness and embarrassment: Perspectives from social Psychology", New York: Cambridge University Press (1990:212) 
Crozier, W. R., \& Alden, L. E., "International handbook of social anxiety”. West Sussex, England: John Wiley \& Sons LTD (2001:198)

Crozier, W. R., \& Alden, L. E., "The essential handbook of social anxiety for clinicians". West Sussex, England: John Wiley \& Sons LTD (2005:217)

Crozier, W.R., "Shyness and self-esteem", British Journal of Social Psychology, 20:220-2 (1981)

Crozier, W.R.. "Shyness and Self esteem in middle childhood", British Journal of educational Psychology, 21,118-121 (1995).

Crozier, W.R.. "Shyness and Self esteem in middle childhood", British Journal of educational Psychology, 21,118-121 (1995).

Harris, P. R., "Shyness and psychological imperialism: On the dangers of ignoring the ordinary language roots of the terms we deal with", European Journal of Social Psychology, 14, 169-181 (1984)

Harris, P. R., "Shyness and psychological imperialism: On the dangers of ignoring the ordinary language roots of the terms we deal with", European Journal of Social Psychology, 14, 169-181 (1984)

Kimberley, Arbeau, Robert, Coplan, "Shyness in adolescents" Carleton University, Ottawa (2005:39)

Marshall, J. R.. Social Phobia: "From Shyness to Stage Fright". New York: Basic Books (1994:76)

"Oxford Advanced Learner's Dictionary" (6th ed.). New York, Oxford University Press (2000:83)

Rubin, K. H., \& Coplan, R. J.. "The development of shyness and social withdrawal" New York: The Guilford Press (2010:324).

Scott, R., "Shyness, Social acceptance \& self-esteem in early adolescence: Interrelationships \& the role of parents", Dissertation doctor of philosophy Athens, Georgia (2003:159)

Scott, S., "The Medicalization of shyness: from social misfits to social fitness". Sociology of Health \& Illness, 28(2), 133-153 (2006)

Volbrecht, M. M., \& Goldsmith, H., "Early temperamental and family predictors of shyness and anxiety" Developmental Psychology, 46(5), 11921205 (2010)

Wood, J., "Effect of anxiety reduction on children's school performance and social adjustment", Journal Developmental psychology, 42(2), 345-349 (2006) 
Zimbardo, P.G. "Shyness: What it is, what to do about it, Reading", MA:

Addison-Wesley (1977:71)

Zimbardo, P.G. "The Stanford Shyness Project", in W.H. Jones, J.M. Cheek and S.R. Briggs (eds) Shyness: Perspectives on Research and Treatment, New York: Plenum Press (1986: 17 - 25)

Zimbardo, P.G. and Shirley, R.. “The Shy Child”, New York: McGraw-Hill (1981: 317)

Zimbardo, P.G., Pilkonis, P.A. and Norwood, R.M. "The social disease called Shyness", Psychology Today, 8:68-72 (1975)

Zimbardo, P.G., Pilkonis, P.A. and Norwood, R.M., "Shackles of Shyness", Psychology Today, UK edition, 1 (6): 24-7 (1975)

Zimbardo, P.G., Pilkonis, P.A. and Norwood, R.M., "The Silent Prison of Shyness", Office of Naval Research Technical Report Z-17, Stanford University (1974:83) 